\title{
XII
}

\section{DO DIREITO À MORADIA À PRECARIZAÇÃO DAS \\ CONDIÇÕES DE VIDA: O COTIDIANO DOS \\ MORADORES DO PMCMV NO JÓQUEI*}

\section{Débora Rodrigues de Araujo ${ }^{1}$}

\section{INTRODUÇÃO}

O presente capítulo se constitui com a perspectiva de ampliar as reflexões iniciadas no Núcleo de Estudos e Pesquisas sobre Favelas e Espaços Populares (NEPFE), sobre o tema da questão urbana que também perpassou minha trajetória em campos de estágios, atuação profissional e vivência. As experiências profissionais em territórios de favelas e a participação no NEPFE foram instigando uma percepção crítica sobre as diferentes formas de intervenção do Estado nesses espaços.

O discurso hegemônico da mídia e de parte dos estudiosos sobre favela tratam esses territórios como o lugar da ausência e não de intervenção do Estado. Mas no cotidiano desses espaços identificamos a presença do poder público com a execução de políticas públicas precárias, de baixa qualidade e fragmentadas, do qual é exemplo o Programa Minha Casa Minha Vida (PMCMV).

A inserção empírica e o aprofundamento teórico possibilitaram compreender que a constituição das favelas e espaços populares fazem parte do desenvolvimento desigual e combinado do capitalismo. Assim, entende-se que as transformações que ocorreram no espaço urbano não acontecem de maneira natural, mas que são produto do processo de industrialização ao mesmo tempo

*DOI - 10.29388/978-65-86678-35-2-0-f.267-286

${ }^{1}$ Assistente social, Mestre em Serviço Social pelo Programa de Pós Graduação em Serviço Social e Desenvolvimento Regional pela Universidade Federal Fluminense (PPGSSDR) E-mail: deborarodrigues_as@yahoo.com.br 
em que os moradores das favelas também são produtores da riqueza e simultaneamente consumidores.

Assim, partindo dessas considerações este texto versa sobre algumas reflexões do Programa Minha Casa Minha Vida situado no Bairro do Jóquei no Município de São Gonçalo no Rio de Janeiro. Programa este que se apresenta como a garantia de acesso à casa própria para famílias de baixa renda, localizados nas áreas periféricas da cidade, as quais possuem baixa cobertura dos serviços públicos e precária infraestrutura urbana.

Parte-se do pressuposto que, contraditoriamente, a política de habitação no Brasil responde a necessidade de ampliação do capital na medida em que aquece o mercado da construção civil e o mercado imobiliário. E por atuar construindo moradias precárias, aprofunda o processo de desigualdade socioespacial da cidade. Nesse cenário, entende-se que há um processo em curso de transformação urbana aonde o direito à moradia vem acompanhado da precarização das condições de vida da população mais pobre marcando o território. Segundo Haesbaert (2006, p. 16), o território é analisado em uma perspectiva "[...] intrinsecamente integradora, que vê a territorialização como o processo de domínio (político-econômico) e \ou de apropriação (simbólico-cultural) do espaço pelos grupos humanos"

Neste sentido, o artigo se propõe a analisar questões a partir de alguns eixos de análise. $\mathrm{O}$ primeiro diz respeito à breve caracterização da Cidade de São Gonçalo (SG) a partir da teoria do desenvolvimento desigual e combinado. No segundo eixo pretende-se pontuar e traçar a algumas considerações sobre o cotidiano dos moradores que residem no empreendimento do PMCMV popularmente conhecido como "predinhos" do Jóquei/ SG.

Tendo como referência o materialismo histórico e dialético como método de análise, a proposta deste estudo teve como perspectiva metodológica reflexões e análises sustentadas em uma abordagem de natureza qualitativa, utilizando-se de pesquisa documental e bibliográfica para a sua elaboração, assim como a realização de visitas ao território e utilização do recurso de mídias sociais com relatos de moradores. 


\section{1- SÃO GONÇALO: UMA CIDADE MARCADA PELO DESENVOL- VIMENTO URBANO DESIGUAL}

Analisar São Gonçalo é refletir particularmente sobre uma cidade que, para ser compreendida, deve ser inserida na constituição das cidades e do espaço urbano como fruto do desenvolvimento do capitalismo no Brasil, marcado pela maneira desigual como a sociedade brasileira se formou. A constituição dos distintos territórios onde vivem as diferentes classes sociais expressam o aprofundamento da desigualdade e a segregação sócio espacial característica do país. Assim, ao analisar a constituição urbana no município de São Gonçalo partimos do pressuposto de que as cidades se constituem como fruto do processo de desenvolvimento desigual e combinado do capitalismo no Brasil, já que existe uma histórica desigualdade produzida pela conformação desigual do espaço urbano, nos termos de Harvey (2006).

As condições sociais, econômicas e culturais fazem com que o crescimento das forças produtivas se desenvolva de forma diferenciada na realidade de cada sociedade. Realidade essa que apresenta características distintas de acordo com cada nação, a partir das suas conformações históricas, do grau de desenvolvimento das forças produtivas e da relação entre as classes essenciais antagônicas do sistema capitalista, explicitando uma forma desigual e ao mesmo tempo combinada de constituição do sistema capitalista mundial.

A maneira desigual como o país se formou, aponta necessariamente para uma maneira desigual na ocupação urbana das cidades. "A desigualdade do desenvolvimento entre os continentes e países é acompanhada por um semelhante crescimento desigual dos distintos elementos dentro de cada grupo social ou organismo nacional.” (NOVACK, 1988, p. 27)

Essa desigualdade combinada conforma também o espaço urbano, gerando o que Harvey (2006) identifica como desenvolvimento geográfico desigual, da qual a cidade do Rio de Janeiro pode ser considerada uma expressão.

Assim, pensando na particularidade da formação do espaço urbano no Rio de janeiro até a metade do século XIX, é possível identificar que quase todos os habitantes da cidade viviam no mesmo espaço, conhecido atualmente como zona central e portuária. Nesse período, a desigualdade social já era pro- 
funda, pois a exploração do trabalho escravo era a principal forma de geração de riqueza.

No final do século XIX com a abolição da escravidão (1888) e com a Proclamação da República (1989) a cidade do Rio de Janeiro cresceu muito, principalmente com a chegada de imigrantes Europeus e os ex-escravos. Esses "trabalhadores livres" que não conseguiram se incorporar nos espaços de produção foram ocupando as moradias precárias da cidade. Apesar da expansão geográfica que a cidade começou a desenvolver, ainda era grande o número de habitantes nas áreas centrais e a forma mais habitual de moradia popular à época era o cortiço ${ }^{2}$.

Campos (2010) ressalta que há muitos estudos que discutem a questão da urbanização do Rio de Janeiro, mas poucos se dispõem a especificar quem eram os pobres que iniciaram o processo de adensamento da ocupação da cidade:

Os negros e pardos (mulatos) acorrem à cidade principalmente a do Rio de Janeiro, alojando-se nos cortiços. Merece ainda destaque a restrição do acesso à terra pelos escravos, que, na falta, também procuravam a cidade em número cada vez mais significativo em busca de trabalho e de moradia. (CAMPOS, 2010, p. 58)

A cidade do Rio foi crescendo à medida que se industrializava sendo necessário adequar à sua conformação urbana às necessidades reais de concentração do capital, conforme aponta Abreu (2008, p. 60):

O rápido crescimento da cidade em direção à zona sul, o aparecimento de um novo e elitista meio de transporte (o automóvel), a sofisticação tecnológica do transporte de massa que servia às áreas urbanas (o bonde elétrico), e a importação cada vez maior da cidade no contexto internacional não condiziam com a existência de uma área central ainda com características coloniais, com ruas estreitas e sombrias, e onde se misturavam as sedes dos poderes político e econômico com carroças, animais e cortiços.

2 Os cortiços eram casas feitas com materiais de baixa qualidade, algumas de madeira, autoconstruídas que serviam de habitação coletiva para a população pobre. 
Abreu (2008) aponta que foi no governo de Pereira Passos, prefeito do Rio de Janeiro entre 1902-1906, que as políticas de reformas urbanas começaram a ser desenvolvidas pelo Estado. Sob o título de "Embelezamento e Saneamento da Cidade", iniciava uma série de reformas na cidade do Rio de Janeiro, dentre elas a remoção dos cortiços da cidade. Com a remoção dos cortiços a população pobre começa a ocupar os morros da cidade. Essa população pobre, formada em sua maioria por ex-escravos livres, não incorporados no processo de produção, também aumentou com a chegada dos combatentes da Guerra de Canudos, que de acordo com Valladares (2005) formou a primeira favela da cidade, conhecida hoje como morro da Providência. ${ }^{3}$

Com as remoções dos cortiços os morros eram a alternativa para grande parte da população que vinha morar no Rio de Janeiro atraída pelo desenvolvimento industrial e a possibilidade de emprego. Esses segmentos da classe trabalhadora desprovidos de condições de ocupar espaços de moradia privilegiado foram habitando espaços mais precarizados.

A ocupação dos espaços periféricos se expandiu com a ampliação dos sistemas de transportes e a ocupação de loteamentos populares destinados a segmentos da classe trabalhadora. Gradativamente, foi se formando o que hoje é intitulado como Região Metropolitana do Rio de Janeiro ${ }^{4}$ que abrange a cidade de São Gonçalo, objeto deste estudo.

Com a população composta por aproximadamente 1.091.737 habitantes $^{5}$, São Gonçalo é o segundo município mais populoso do estado do Rio de Janeiro. A região, que antes da chegada dos portugueses era ocupada pela população indígena Tupinambás, também conhecidos como Tamoios, tem seu pro-

3 O morro foi ocupado, primeiramente, pelos moradores desalojados dos cortiços e posteriormente soldados que voltavam da guerra de Canudos. Os antigos combatentes vieram para o Rio de Janeiro e ocuparam o morro com o objetivo de pressionar o Ministério da Guerra para seus soldos atrasados e por lá acabaram ficando. O Morro da Providência foi batizado no final do século XIX, como Morro da Favella.

${ }^{4}$ Conforme a Lei Complementar $n^{\circ} 105$ de 2002, a região Metropolitana do Rio de Janeiro é composta por 17 municípios: Rio de Janeiro, Belford Roxo, Duque de Caxias, Guapimirim, Itaboraí, Japeri, Magé, Nilópolis, Niterói, Nova Iguaçu, Paracambi, Queimados, São Gonçalo, São João de Meriti, Seropédica, Mesquita e Tanguá.

5 Fonte: < https://cidades.ibge.gov.br/brasil/rj/sao-goncalo/panorama $>$. Acesso em 06 de setembro de 2020 . 
cesso de exploração econômica através da construção de portos e fazendas. Nesse período destaca-se o processo primário exportador de cana-de-açúcar.

Apesar de sua primeira emancipação política ter sido no ano de 1890 quando São Gonçalo é desmembrado de Niterói, ocorrem vários processos de disputas políticas e somente no ano de 1929 é instituída como cidade. ${ }^{6}$ Foi a partir dos anos 1930, processo de grande crescimento industrial do Rio de Janeiro, que São Gonçalo tem sua expansão urbana, acompanhando a lógica de desenvolvimento das cidades modernas capitalistas que segue uma lógica de estruturação a partir do binômio industrialização/urbanização.

No período há uma população que crescia na cidade do Rio e não conseguia ocupar os espaços centrais da cidade, já encarecidos, e foram conformando espaços de moradia na região metropolitana do estado. As rodovias e as ferrovias já existentes possibilitaram a expansão de outros espaços. Em São Gonçalo esse processo de ocupação ocorre através dos loteamentos populares.

É importante considerar que a ocupação de São Gonçalo não ocorre somente pelo processo de industrialização da cidade do Rio. O município também se desenvolvia industrialmente desde os anos 1920 com a instalação de indústrias de cerâmicas, metalúrgicas e fábricas de pescado. Em 1940, chegou a ocupar o segundo maior produto industrial do estado, recebendo o título de "Manchester Fluminense" por alcançar importante patamar industrial.

O processo de ampliação da infraestrutura urbana não acompanhou de maneira proporcional o crescimento populacional da cidade. $\mathrm{Na}$ sua construção histórica, o processo de loteamento popular se construiu a partir da lógica da especulação e as áreas centrais da cidade se desenvolvendo com maior infraes trutura urbana. Esta foi ocupada por pessoas com maior poder aquisitivo na época. Nesse processo, ocorreu a ocupação desordenada nas áreas mais afastadas do centro pela população mais pobre.

Segundo Harvey (2006), a urbanização é uma forma importante de reprodução do capitalismo. As cidades passam por diferentes processos de transformações para atender às demandas do capitalismo e não para melhorar a vida de seus habitantes, conforme explicita o exemplo de muitas cidades brasileiras, assim como São Gonçalo.

\footnotetext{
${ }^{6}$ Em 1929, a Lei n ${ }^{\circ} 2335$, de 27 de dezembro, concede a categoria de cidade a todos as sedes do município.
} 
Quanto aos meios da realização, vende-se a ideia de que é mais racional ou melhor, mais lucrativo priorizar obras que drenem grandes quantidades de recursos do Estado do que utilizar os mesmos recursos na ampliação e na manutenção de serviços básicos indispensáveis a uma população que não pode pagar planos de saúde ou escolas privadas e continua sem acesso à infraestrutura urbana. (BARREIRA, 2013, p. 143)

Consideramos que a construção urbana das cidades não acontece de maneira natural, mas são impulsionadas para a conformação de uma cidade desigual. Nesse sentido, compreendemos que a constituição do município de São Gonçalo é mais uma expressão do desenvolvimento territorial desigual do capitalismo.

Como afirma FARAGE (2012, p. 40):

A segregação na cidade produz tanto o desenvolvimento e a apropriação desiguais do território, como dos seus recursos, fazendo com que a cidade se constitua de espaços, locais e equipamentos que ratificam e evidenciam as desigualdades econômicas e sociais. Nesse sentido, a cidade não se constitui como fruto de um processo natural de desenvolvimento industrial e urbano, mas sim como fruto das necessidades do desenvolvimento capitalista.

São Gonçalo não se sustentou como importante polo industrial por muito tempo. A partir dos anos 1970 o emprego industrial declinou e a cidade aos poucos foi ganhando uma nova característica que é o de uma população que sai para trabalhar em outra cidade passando a receber o título de "cidade dormitório". Foi no ano de 1974, com a inauguração da Ponte Presidente Costa e Silva, que liga a cidade de Niterói ao Rio de Janeiro, que a cidade se interligou aos principais centros urbanos da região, intensificando o fenômeno da cidade dormitório.

O município com poucas ofertas de emprego e renda, com precária infraestrutura urbana, atraía uma população migrante que vinha em busca de trabalho no Rio de Janeiro. A cidade foi se conformando como espaço de moradias mais baratas para frações da classe trabalhadora que não conseguiam pagar para morar nem nos espaços mais precários da cidade do Rio de janeiro e até mesmo de Niterói - cidade adjacente. 
No que se refere à intervenção do Estado na questão habitacional, a cidade de São Gonçalo construiu uma história de precário investimento estatal. Ao mesmo tempo que permitiu as concessões para ampliações dos loteamentos urbanos, não investiu em uma política urbana para atender o crescimento da população que aumentava.

Conforme Plano Diretor do Município de São Gonçalo realizado em 2010 a cidade se divide em 5 distritos: $1^{\circ}$ distrito - São Gonçalo (Sede); $2^{\circ}$ distrito - Ipí́ba; $3^{\circ}$ distrito - Monjolo; $4^{\circ}$ distrito - Neves e $5^{\circ}$ distrito - Sete Pontes.

Com mais de 1 milhão de habitantes, os dados do IBASE de 2014 expressam que o déficit habitacional de São Gonçalo era de aproximadamente 20 mil unidades de moradia. Além da precária situação habitacional, a cidade apresenta insuficiente abastecimento de água e serviço de esgotamento sanitário ${ }^{7}$, coleta de lixo aquém das necessidades dos moradores tem como transporte de ligação com outros municípios, a exclusividade de empresas privadas de ônibus privados, apresentando mobilidade urbana desorganizada nas regiões mais afastadas das áreas centrais da cidade. Há que se destacar o projeto de construção da Linha 3 do metrô que possibilitaria a ligação entre a cidade do Rio de Janeiro e Niterói e entre Niterói e São Gonçalo, que há mais de 12 anos foi proposto e não foi concretizado. Contraditoriamente, foi construída a linha 4 do metrô na cidade do Rio de Janeiro que conecta a estação General Osório, na zona sul do Rio, à estação Jardim Oceânico, localizada na Barra da Tijuca. Esta linha atende uma quantidade ínfima de pessoas se comparado a densidade populacional dos trabalhadores e trabalhadoras que saem de São Gonçalo rumo a cidade do Rio de Janeiro diariamente. Nem mesmo o movimento pendular diário, que provoca longos e densos engarrafamentos nas rodovias, motivou a construção da linha 3 do metrô, mas o atendimento a uma população economicamente favorecida fez o poder público investir milhões na construção da linha 4.

As desigualdades são as marcas da cidade de São Gonçalo. Responsável por acolher uma das maiores favelas planas da América Latina, o Jardim Catarina e por sua precária rede de atendimento de serviços públicos, a cidade é mer-

\footnotetext{
${ }^{7}$ Conforme dados do IBASE (Instituto Brasileiro de Análises Sociais e Econômicas) a cidade possui $20 \%$ da população em moradias com esgoto a céu aberto.
} 
cada pelos sucessivos e longos cortes de luz, pelo limitado recolhimento de lixo, pela escassa e precária rede de educação e de assistência social, entre outros.

O município de São Gonçalo é marcado por um dos mais baixos salários pagos a redes de funcionalismo público, além de ser característico a contratação terceirizada, uma vez que os concursos públicos não são a marca da garantia de direitos no município.

Segundo Corrêa (1995, p. 6), o espaço deve ser compreendido “[...] como forma espacial em suas conexões com a estrutura social, processos e funções urbanas", sendo ainda considerado como um "[...] paradigma de consenso e de conflito". É mediante esses apontamentos, que abordaremos a seguir algumas reflexões sobre as particularidades do cotidiano dos moradores e a questão da moradia no bairro do Jóquei no município de São Gonçalo.

\section{2- MINHA CASA MINHA VIDA EM SÃO GONÇALO: A EXPERIÊN- CIA DOS "PREDINHOS” DO JÓQUEI}

Conforme as reflexões construídas acima, a processualidade histórica de conformação desigual do município de São Gonçalo apresenta processos diferenciados na formação dos bairros da cidade. É possível afirmar que os bairros mais próximos das áreas centrais do município possuem um maior investimento de infraestrutura urbana em detrimentos dos demais.

O bairro do Jóquei, localizado no terceiro distrito de São Gonçalo teve sua ocupação ampliada a partir do projeto de construção do Jóquei Clube de São Gonçalo no ano de 1957. O projeto do hipódromo no Bairro não foi efetivado, sendo o espaço transformado em loteamentos. Sua ocupação com loteamentos populares foi sendo realizada por migrantes, em sua maioria vindo do Nordeste, que viam em busca de mercado de trabalho no Rio de Janeiro. O território retrata a conformação de processos desiguais de espaço de moradia e é marcado pelo baixíssimo investimento do poder público.

Com relação aos serviços públicos oferecidos, o bairro que possui aproximadamente 3.758 domicílios com mais de 11 mil habitantes ${ }^{8}$, é formado apenas por duas escolas estaduais, uma escola municipal, duas Unidades Básicas de Saúde e somente uma creche comunitária conveniada com a Prefeitura de

${ }^{8}$ Conforme Censo do IBGE de 2010. 
São Gonçalo que está há aproximadamente sete meses sem receber repasses de verbas do munícipio.

Quanto a política de Assistência Social, os CRAS (Centro de Referência de Assistência Social) e CREAS (Centro de Referência Especializado de Assistência Social) que atendem diversos bairros da cidade, estão localizados em outro bairro, Tribobó, a cinco quilômetros de distância sendo necessário a utilização de transporte público para acessá-lo. Destaca-se que os CRAS, em sua legislação específica deve atender aproximadamente 5.000 famílias por território e conforme último censo do IBGE, que já possui mais de 10 anos, o bairro do Jóquei tinha uma população habitacional de 11.068 pessoas.

Um elemento marcante no bairro, que traz muitos problemas no cotidiano da vida dos moradores é a existência do comércio varejistas de drogas. Há presença de grupos civis armados com duas facções rivais conforme se noticia nas mídias locais, além da presença de milícias. O conflito armado entre as facções rivais é constante e recorrente, assim como confrontos entre policiais e grupos armados. Cabe informar que no bairro há uma DPO (Companhia Destacada de Policiamento Ostensivo) que conta com efetivos de policiais militares, mas os conflitos quase diários demonstram a fragilidade na forma como o Estado "garante" a segurança pública no território.

Consideramos que as precárias condições de acesso aos serviços não dizem respeito apenas aos equipamentos públicos não existentes no bairro, mas a baixa qualidade em seu funcionamento, assim como o distanciamento produzido pela baixa oferta de linhas de ônibus que dificulta o acesso da população na busca de serviços em outros espaços da cidade. No bairro do Jóquei existe apenas uma linha de ônibus intermunicipal e duas linhas municipais. Os serviços de transporte individuais como Uber estão suspensos pelo próprio aplicativo justificado pelo bairro ser considerado área de risco.

São inúmeras violações de direito perpetradas pelo próprio Estado que deveriam garantir o Direito a Cidade. Nesse sentido Harvey (2014) nos ajuda com uma reflexão importante:

O Direito à Cidade é, portanto, muito mais do que um direito de acesso individual ou grupal aos recursos que a cidade incorpora: é um direito de mudar e reinventar a cidade mais de acordo com os nossos profundos desejos. Além disso, é um direito mais coletivo do que individual, uma 
vez que reinventar a cidade depende inevitavelmente do exercício de um poder coletivo sobre o processo de urbanização. (HARVEY, 2014, p. 28)

Ainda sobre a caracterização do bairro, é expressivo o número de empreendimentos de pequeno porte, especialmente bares e salões de beleza. Assim como é grande o número de igrejas, em sua maioria evangélicas. As igrejas evangélicas cumprem um papel importante nas favelas. No Jóquei esse espaço é considerado o espaço de acolhida, de acesso a alimentos, e construção de lideranças que em alguma medida exercem poder.

Com relação aos espaços de lazer, há apenas uma praça em estado de conservação ruim. Nos terrenos vazios que eram utilizados para jogos de futebol foram construídos os empreendimentos do PMCMV. A falta de investimentos em esporte e lazer aponta o quanto essa política é lateralizada para as áreas mais pobres.

Realizando um destaque a questão da moradia, objeto de preocupação neste estudo, até o ano de 2014 as construções habitacionais do Jóquei eram predominadas por casas autoconstruídas, distribuídas espacialmente com no máximo dois andares. A partir da construção das unidades habitacionais do Programa Minha Casa Minha vida o bairro passou a ter uma nova configuração visual com imóveis verticalizados já que foram construídas 2701 unidades habitacionais.

O extinto Ministério das Cidades ${ }^{9}$ que foi criado no ano de 2003, primeiro ano do governo Lula (2003-2011), representou um novo formato de implantação da política habitacional e infraestrutura urbana no país. Com o plano nacional de habitação criado em 2009, surgiu o Programa "Minha Casa, Minha Vida" que anunciava reduzir o déficit habitacional brasileiro proporcionando à população de baixa renda condições de moradia digna.

Destaca-se que, em 2017, a Fundação Getúlio Vargas (FGV) estimou que o déficit habitacional no Brasil estaria em 7,7 milhões de domicílios e a Fundação João Pinheiro (FJP) mostra que em 2015, havia 7,9 milhões de imóveis vagos no Brasil. Segundo a FJP, desse total, 6,893 milhões de imóveis estão em condições de serem ocupados, e 1,012 milhão passam por reforma ou ainda estão em construção. Em seus estudos, a FJP utiliza os dados da Pesquisa Naci-

${ }^{9}$ O órgão foi extinto com a edição da Lei no 13.844 , de 18 de Junho de 2019. 
onal por Amostra de Domicílios (Pnad), feita pelo IBGE, e ressalta que os números não incluem os "imóveis em ruínas." O que significa dizer que mesmo com o esforço do programa, o Brasil ainda conta com um problema de grande importância a ser solucionado.

A política de habitação desenvolvida pelo Programa Minha Casa Minha Vida trouxe na sua prática uma vinculação com o mercado imobiliário, sem participação da população, onde as construtoras escolheram a localização dos terrenos, geralmente os mais afastados, com valores mais baixos, em territórios com infraestrutura precária. Um projeto que tem sua marca no lucro e produz ainda mais desigualdades socioespaciais.

Mediante estas ponderações, pensando nas particularidades de São Gonçalo, em 2014 iniciaram a conclusão dos 08 conjuntos habitacionais implantados no bairro do Jóquei. Os apartamentos foram destinados as famílias com faixa de renda de até mil e oitocentos reais inscritas no Cadastro Único (CAd Único) do Governo Federal e teve como beneficiárias as famílias vitimadas por desastres e calamidades públicas ambientais ocorridos no município.

Durante a construção das unidades habitacionais não houve criação de qualquer equipamento público para o atendimento do conjunto dos novos moradores. Os poucos e precários serviços oferecidos pelo Estado para a população que já residiam no território passaram a ser disputados também pelas novas 2701 famílias que entre os anos de 2014 e 2016 mudaram para os novos empreendimentos habitacionais.

Além disso, os imóveis entregues apresentaram uma série de problemas estruturais e já nos primeiros conjuntos habitacionais inaugurados entregues foram relatadas várias situações: falta de condições técnicas para a instalação da rede elétrica, imóveis entregues sem emissão do habite-se (auto de construção de obras) e falta de iluminação nas partes comuns do condomínio.

No mês de março de 2016 houve a primeira forte chuva após a inauguração dos condomínios e a maior parte dos apartamentos térreos foram atingidos trazendo uma inundação. Os moradores perderam todos os móveis, documentos pessoais, além da enchente ter afetado as tubulações da companhia de abastecimento de água, onde as famílias de todos os conjuntos habitacionais ficaram sem acesso à água. 
Importante ressaltar que parte das famílias beneficiadas com imóveis haviam sido vítimas de desastres no município em anos anteriores e perderam suas casas. Com a enchente nos apartamentos reviveram as mesmas perdas. Além disso, há que se considerar que os apartamentos térreos foram destinados ao atendimento as pessoas com deficiência e idosos, os principais atingidos com a inundação dos conjuntos habitacionais.

$\mathrm{Na}$ ocasião havia alguns imóveis ainda em fase final de construção nos conjuntos habitacionais e as famílias desalojadas ocuparam os empreendimentos vazios. A situação motivou que outras famílias atingidas pela enchente e que não residiam nos conjuntos habitacionais ocupassem os apartamentos inacabados. No dia 17 de maio de 2016, oficiais de justiça e agentes da polícia militar e federal com mandados de reintegração de posse retiraram todas as pessoas que estavam na ocupação.

As famílias que residiam no empreendimento antes da enchente voltaram para os imóveis atingidos pela inundação, e o município não reconheceu as condições em que os imóveis se encontravam. Essa realidade das condições de moradia já nos primeiros anos de entrega dos empreendimentos se mantém até os dias de hoje, sendo relatado pelos moradores a precariedade nas condições estruturais dos apartamentos. Além disso, os conflitos armados que ocorrem quase que diariamente nos arredores do empreendimento são sinalizados por toda a população como um local difícil de viver.

Os conjuntos habitacionais passaram a ser denominados popularmente como "predinhos" e a oferta de venda ou aluguel dos imóveis passou a promover constantes mudanças da população residente, não tendo os moradores do local construído um vínculo identitário com o território e nem construíram alguma possibilidade de organização coletiva.

Entendemos o cotidiano como espaço que reflete as condições objetivas da realidade social vivenciada, e observamos que o território do Jóquei passou a apresentar os reflexos das contradições impressas pelo Estado ao construir quase três mil novas moradias sem qualquer investimento de infraestrutura para a população. O Programa Minha Casa Minha Vida, passou a ser apelidado pela população local como "Minha Casa Meu pesadelo".

Segundo FARAGE (2012, p. 150): 
O cotidiano é entendido como o espaço de produção real da vida, da reprodução da ideologia, da construção das relações sociais de existência, considerando diferentes aspectos da vida, como a família, a escola, a religião, o trabalho, a cultura e as formas de organização coletivas. Nessa perspectiva tem-se no desenvolvimento das ações públicas, nos equipamentos do Estado, um interlocutor essencial para o processo de produção e reprodução social da vida.

Em uma comunidade da rede social moradores relatam as condições de insegurança por conta dos tiroteios: "Fico muito triste. Muitas pessoas de bem, honesta, sonham em ter sua própria casa e tem que deixar todos os seus sonhos." "Tá muito brabo mesmo, não tem mais hora. Tá todo mundo querendo sair desse lugar. ${ }^{10 "}$

Entende-se que o processo de crescimento da violência não acontece de maneira natural, mas aumenta de acordo com as relações de exploração e desigualdade. O comércio ilegal de drogas se revela como uma atividade viável para os jovens dispostos a se arriscar nessa sociedade do capitalismo flexível. A realidade dos "predinhos" expressa as condições de um país e de uma cidade desigual, com altos índices de homicídio, onde o alvo principal são frações de uma classe que dispõem apenas da sua força de trabalho para sobreviver. Não encontramos dados sistematizados sobre o índice de homicídios no Jóquei, mas o cotidiano demonstra que o alto número de assassinados no território contribuiu para que o município de São Gonçalo, no ano de 2019, liderasse a estatística de mortes em confrontos armados.

A violência e suas diversas manifestações estão diretamente ligadas ao desenvolvimento do capitalismo em nosso país, que vem se utilizando de todas as ferramentas para "eliminar" a concentração de pobres que o processo de acumulação do capital produziu. E para justificar essa violência são construídas formas ideológicas de criminalizar a população que mais sofre as consequências desse processo.

Para Silva (2009, p. 57),

Pela via do processo de sinonímia entre tráfico de drogas e favelas, esses territórios foram sendo, cada vez mais, identificados e representados como definitivamente perigosos e ingovernáveis, afirmando-se a impos-

${ }^{10}$ Comentários em rede social, grupo público do facebook denominado "JÓQUEI SG". Acesso: 10 de setembro de 2020 . 
sibilidade de se estabelecer ali o mesmo padrão de regulação social presente em outras partes da cidade.

Nesse sentido, os moradores dos "predinhos" do Jóquei além de sofrerem com as precárias condições de vida, vivem no seu cotidiano as repercussões do estigma de serem os responsáveis pela piora da realidade do território. É comum que moradores antigos culpabilizem a chegada dos novos habitantes dos empreendimentos como responsáveis pelas mudanças negativas do cotidiano do território, como aponta a fala: "Os apartamentos são bonitos, mas aqui no Jóquei tá o pior bairro." "Moro 30 anos e agora tá horrível. Nem vou a rua. Só por muita necessidade." "Gente, a coisa tá ruim no Jóquei e infelizmente é o predinho." "Infelizmente é verdade. O jóquei era bom até os prédios. Tem até gente boa, mas baratas sem multiplicam... ${ }^{11 "}$

As frases acima são de moradores que discutem em uma comunidade da rede social local o crescimento dos confrontos armados. No geral os embates se dão entre os moradores dos "predinhos" e os que residem em outras comunidades do entorno. Vemos também a criminalização dos moradores por parte de pessoas de outros territórios, como exemplo, vimos o relato de um jovem que em uma entrevista de emprego é repreendido pelo local que reside: "Um dia desses fui em uma entrevista de emprego e me perguntaram onde moro. Falei que moro no Jóquei e a mulher se espantou questionando se eu morava nos predinhos, pois lá era muito perigoso." $" 12$

Conforme já dito, a construção social sobre os moradores de favela e periferias também determina a forma como o Estado desenvolve as políticas públicas. Essa resposta à parte da classe trabalhadora que se encontra nos territórios mais pobres historicamente foi desenvolvida através do autoritarismo e controle.

Por fim, um grande problema apresentado pelas famílias foi a dificuldade das mesmas no acesso à educação. Muitas crianças recorrem a única escola pública do território, mas não conseguem ser atendidas. Assim, andam alguns quilômetros ou dependem dos poucos ônibus que circulam no bairro para se deslocar para outros bairros e estudar.

\footnotetext{
${ }^{11}$ Comentários em rede social, grupo público do facebook denominado "JÓQUEI SG". Acesso: 10 de setembro de 2020

${ }^{12}$ Iìdem ao anterior.
} 


\section{CONSIDERAÇÕES FINAIS}

Traçando algumas considerações não conclusivas sobre o direito à moradia e precarização das condições de vida mediante a análise do cotidiano dos moradores do PMMV no Jóquei, é possível reafirmar que São Gonçalo reitera o exemplo de que o capitalismo não se desenvolve sem produzir territórios desiguais. Para além disso, "os direitos de propriedade privada e a taxa de lucro se sobrepõem a todas as outras noções de direito" (HARVEY, 2014, p. 73).

Assim, o Jóquei, seria mais uma expressão da segregação urbana que se manifesta em uma cidade já segregada. São Gonçalo, como cidade periférica, apresenta uma série de problemas importantes quanto ao seu desenvolvimento urbano já que a mesma cresceu de forma desproporcional ao investimento público em infraestrutura e políticas sociais. Na cidade não há um terminal rodoviário, não existe um hospital de grande porte, as vias públicas possuem pavimentação de má qualidade ou incompletas, a entrega de correspondências é insuficiente, a coleta de lixo é irregular e diversos serviços públicos estão aquém da sua demanda. Toda essa caracterização da cidade está presente no bairro do Jóquei, mas de forma acentuada e que piora a cada dia já que não há projetos e programas de urbanização e desenvolvimento das demais políticas sociais para o território.

Harvey (1996) aponta que a urbanização é uma forma importante de reprodução do capitalismo já que as cidades passam por diferentes processos de transformações para atender às demandas do capitalismo e não necessariamente para melhorar a qualidade de vida de seus habitantes.

Quanto aos meios da realização, vende-se a ideia de que é mais racional ou melhor, mais lucrativo priorizar obras que drenem grandes quantidades de recursos do Estado do que utilizar os mesmos recursos na ampliação e na manutenção de serviços básicos indispensáveis a uma população que não pode pagar planos de saúde ou escolas privadas e continua sem acesso à infraestrutura urbana. (BARREIRA, 2013, p. 143)

Quanto aos moradores dos empreendimentos do Programa Minha Casa Minha Vida, estes encontram no programa uma opção de moradia oferecida pelo poder público como concretização de acesso à moradia a população 
mais pobre. Porém, este se apresenta prioritariamente como uma nova organização do espaço urbano em um contexto de relações sociais capitalistas e de sua dinâmica de desenvolvimento, visando a produção de novas estruturas e padrões de empresariamento urbano.

$\mathrm{Na}$ experiência analisada foi possível observar que a construção dos empreendimentos em um território afastado do centro do município, com baixa oferta de linhas de ônibus e políticas públicas entre outras debilidades, não considerou as necessidades já existentes dos moradores do Jóquei. Houve um grande aumento populacional, quase dobrando o número de moradores, sem qualquer investimento governamental para atender a demanda da população que chega junto com o empreendimento.

Por fim, o discurso realizado em torno do Programa Minha Casa Minha Vida como política habitacional de combate à desigualdade, apresenta muito mais o investimento e desenvolvimento econômico, do que a melhoria das condições de vida da população. O cotidiano dos moradores dos "predinhos" do Jóquei reflete esse modelo de Estado que viola direitos e precariza as condições de vida da população mais pobre e expressa as contradições do que o projeto se propõe e o que ele realmente é.

\section{REFERÊNCIAS}

ABREU, M. de A. Evolução Urbana do Rio de Janeiro. Rio de Janeiro: IPP, 2008.

ALERJ. Lei Complementar $\mathbf{n}^{\mathbf{0}} 105$ de 2002. Assembleia Legislativa do Estado do Rio de Janeiro, Rio de Janeiro, 2002. Disponível em:

< http://aleriln1.aleri.ri.gov.br/contlei.nsf/f25571cac4a61011032564fe0052c89 c/623fa9ce62b1c36683256ca6005b080d?OpenDocument> . Acesso em: 20 out. 2020 .

BARREIRA, M. Cidade Olímpica: sobre o nexo entre reestruturação urbana e violência na cidade do Rio de Janeiro. In: BRITO, F.; ROCHA, P. de O. (orgs.). Até o último homem. São Paulo: Boitempo, 2013, p. 124-145.

BRASIL. Ministério das cidades. Plano Nacional de Habitação. Brasília, 2009. Disponível em: 
$<$ https://urbanismo.mppr.mp.br/arquivos/File/Habitacao/Material de Apoi o/PLANONACIONALDEHABITAO.pdf > . Acesso em: 19 out. 2020.

. Lei no 13.844, de 18 de Junho de 2019. Disponível em:

$<$ http://www.planalto.gov.br/ccivil 03/_ato2019-2022/2019/lei/L13844.htm $>$. Acesso em: 20 out. 2020.

. Lei no 2335, de 27 de dezembro de 1929. Disponível em:

$<$ https://www.saogoncalo.ri.gov.br/?page id=4804> . Acesso em: 22 out. 2020.

CAMPOS, A. Do quilombo à favela: a produção do "espaço criminalizado" no Rio de Janeiro. Rio de Janeiro: Bertrand Brasil, 2010.

CORRÊA, R. L. O Espaço Urbano. São Paulo: Editora Ática, 1995.

FARAGE, E. Estado, território e cotidiano no Complexo de Favelas da Maré. 2012. 253f. Tese (Doutorado em ) - Programa de Pós Graduação em Serviço Social, Faculdade de Serviço Social, Centro de Ciências Sociais, Universidade Estadual do Rio de Janeiro, Curso de Serviço Social, Rio de Janeiro, 2012.

HARVEY, D. Do gerenciamento ao empresariamento: a transformação da administração urbana no capitalismo tardio. Revista Espaço e Debates, n. 39, São Paulo, 1996, p.48-64.

A produção capitalista do espaço. São Paulo: Annablume, 2006.

. Cidades Rebeldes: do direito à cidade à revolução urbana. São Paulo: Boitempo, 2014.

HAESBAERT, R. Omito da desterritorialização do "fim dos territórios" a multiterritorialização. Rio de Janeiro: Editora Bertrand Brasil, 2006.

IBGE. Censo Demográfico da População Brasileira. Instituto Brasileiro de Geografia e Estatística (IBGE). Rio de Janeiro, IBGE, 2010. Disponível em: $<$ https://censo2010.ibge.gov.br/ >. Acesso em: 03 set. 2020.

. Censo Demográfico da População Brasileira. Instituto Brasileiro de Geografia e Estatística (IBGE). Rio de Janeiro, IBGE, 2010. Disponível em: 


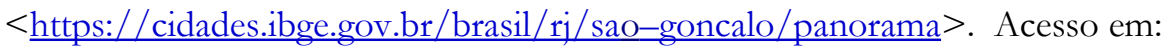
06 set. 2020.

NOVACK, G. A lei do desenvolvimento desigual e combinado da sociedade. São Paulo: Editora Rabisco, 1988.

SILVA, M. L. P. da S. Favela: é geral? É particular? É urbano? In: SILVA, Jailson de Souza, BARBOSA, Jorge Luiz, BITETI, Mariane de Oliveira, FERNANDES, Fernando Lannes (orgs). O que é Favela, Afinal? Rio de Janeiro: Observatório de Favelas, 2009, p.30-35.

VALLADARES, L. do P. A invenção da favela: do mito de origem a favela.com. Rio de Janeiro: Editora FGV, 2005. 